\title{
Pharmaceutical Bar Coding: Moving Forward in Canada
}

Contributions to this column are prepared by the Institute for Safe Medication Practices Canada (ISMP Canada), a key partner in the Canadian Medication Incident and Prevention System. From time to time, ISMP Canada invites others to share learning based on local initiatives. The article presented here is reprinted, with permission, from the ISMP Canada Safety Bulletin 2009;9(4):1-3.

\begin{abstract}
A nalyses of medication incidents such as the inadvertent administration of hydromorphone instead of morphine ${ }^{1,2}$ have led to recommendations that healthcare facilities strategically plan for implementation of advanced technologies such as bar coding at the point of care, prescriber order entry, and electronic medication administration records. The use of bar coding (the most widely recognized machine-readable identifier) ${ }^{3,4}$ in a pointof-care scanning system, combined with a computerized database, allows healthcare professionals to verify that the right drug, in the right dose and by the right route of administration, is being given to the right patient at the right time. ${ }^{5}$ Bar coding, when integrated with other advanced technologies, can serve as an automated independent double check. The purpose of this bulletin is to provide an update on the status of automated identification (e.g., bar coding) of pharmaceutical products in Canada.
\end{abstract}

\section{BACKGROUND}

Bar coding is well established in industries outside of the healthcare sector and is now used in some healthcare-related industries such as retail pharmacy, to enhance efficiency and safety, and in pharmaceutical wholesale operations, to improve supply chain efficiency. The exterior package labels of most prescription medications for sale in Canada include an identifying bar code. However, the same does not hold true for the inner labels on unit-of-use packaging, such as ampoules, vials, and blister packs. As a result, hospitals that have begun to implement bar coding systems have had to generate and print their own bar codes for application to ampoules, vials, and blister packs, as well as for their own pharmacy-prepared products.

Recently, several pharmaceutical manufacturers have demonstrated leadership by adding bar code identification to their products' inner labels. As stated by the National Coordinating Council for Medication Error Reporting and Prevention, "Before healthcare practitioners and organizations can benefit from machine-readable codes, the codes must be physically present in a standard format on unit-of-use medication packaging."

There have been no formally recognized Canadian standards for bar coding specifically developed for medications; however, a number of related initiatives are under way. For example, the Public Health Agency of Canada is taking steps to develop a consensus on standards for bar coding of vaccines.

\section{A NATIONAL COLLABORATIVE EFFORT: THE CANADIAN PHARMACEUTICAL BAR CODING PROJECT}

On January 24, 2008, a stakeholder invitational roundtable, co-chaired by ISMP Canada and the Canadian Patient Safety Institute (CPSI), was convened in Ottawa to discuss and seek pharmaceutical manufacturer consensus on voluntary guidelines for the use of bar codes to label medications at the unit-of-use packaging level. Prior to the roundtable, a document was prepared and circulated to stimulate discussion on how pharmaceutical manufacturers can best meet the needs of Canadian health service organizations that are seeking to improve patient safety by using automated identification technologies in medication dispensing and administration systems. ${ }^{8}$ During the meeting, there was overall agreement that a national standard is urgently needed for bar coding of pharmaceutical products in Canada.

Pursuant to the roundtable, a multiphase project plan for pharmaceutical bar coding in Canada was prepared. The 
project is being guided by an Implementation Advisory Committee, co-chaired by ISMP Canada and CPSI and currently comprising representatives of the following organizations and associations (in alphabetical order):

- Canada Health Infoway

- Canada’s Research-Based Pharmaceutical Companies

- Canadian Association of Chain Drug Stores

- Canadian Association for Pharmacy Distribution Management

- Canadian Generic Pharmaceutical Association

- Canadian Society of Hospital Pharmacists

- Group Purchasing Organization Alliance (currently includes Approvisionnement-Montréal, HealthPRO, and Medbuy)

- Public Health Agency of Canada

In follow-up to the first meeting of this committee, held March 11 and 12, 2009, in Toronto, ISMP Canada and CPSI jointly endorsed the adoption of the GS1 global standard for automated identification (e.g., bar coding) of pharmaceutical products in Canada [see sidebar].

Going forward, work with stakeholders will aim to ensure that the Canadian standard continues to evolve so that user requirements for implementing bar coding within the healthcare system are fully identified and met across all healthcare sectors. A 28-member Technical Task Force, with representation from pharmaceutical manufacturers, supply chain organizations, health and information technology, retail pharmacy, institutional pharmacy, and health standards organizations, [was to] hold its first meeting on May 21 and 22, 2009. The Technical Task Force will define the requirements of the Canadian healthcare constituents in the following areas: bar code components and symbology, database elements, drugs to be included, and packaging levels and bar code placement. The Technical Task Force will also provide input on a pan-Canadian implementation and sustainability plan.

By proactively and cooperatively reaching agreement on the standards to be implemented, the healthcare system can move toward the implementation of bar coding to enhance safety checks during medication-use processes such as compounding, dispensing, and administration, as well as benefiting from enhanced efficiencies along the entire medication supply chain.

This national collaborative effort is envisioned to have multiple strategic phases, during which strategic alliances will be further developed. The ultimate outcome will be widespread utilization of bar coding technology to add another layer of safety to our medication-use systems. Project updates will be available on the websites of both ISMP Canada and CPSI. For more information, please contact ISMP Canada (by telephone 1-866-544-7672 or by email isheppard@ismp-canada.org) or CPSI (by telephone 1-613-730-7322 or by email pleonard@cpsi-icsp.ca)

\section{References}

1. An omnipresent risk of morphine-hydromorphone mix-ups. ISMP Can Saf Bull 2004 Jun [cited 2009 May 4];4(6):1-2. Available from: http://www.ismp-canada.org/download/safetyBulletins/ISMPCSB200406.pdf

\section{Automated Identification of Pharmaceutical Products in Canada}

The Institute for Safe Medication Practices Canada (ISMP Canada) and the Canadian Patient Safety Institute (CPSI), following broad consultation, jointly endorse the adoption of the GS1 global standard for automated identification (e.g., bar coding) of pharmaceutical products in Canada. Going forward, ISMP Canada and CPSI will work with stakeholders to ensure that the Canadian standard continues to evolve so that user requirements for implementing bar coding for enhanced safety of medication use within the healthcare system are fully identified and met across all healthcare sectors.

The Canadian Pharmaceutical Bar Coding Project is a unique opportunity for all stakeholders within the Canadian medication system, from industry to healthcare providers, to collaborate nationally and internationally on a comprehensive strategy for enhanced medication.

2. Shared learning - reported incidents involving hydromorphone. ISMP Can Saf Bull 2006 Dec 28 [cited 2009 May 4];6(9):1-3. Available from: http://www.ismp-canada.org/download/safetyBulletins/ISMPCSB200609Hydromorphone.pdf

3. Neuenschwander M, Cohen MR, Vaida AJ, Patchett JA, Kelly J, Trohimovich B. Practical guide to bar coding for patient medication safety. $A m$ J Health Syst Pharm 2003;60(8):768-779.

4. Implementing a bar coded medication safety program: pharmacist's toolkit. Bethesda (MD): American Society of Health-System Pharmacists Research and Education Foundation; 2004.

5. Bar code label requirements for human drug products and biological products; final rule. Supplementary information. Federal Register 2004 Feb 26 [cited 2009 May 5];69(38):9119-9171 (codified at 21 CFR parts 201, 606). Available from: http://www.fda.gov/OHRMS/ DOCKETS/98fr/04-4249.htm

6. Promoting and standardizing bar coding on medication packaging: reducing errors and improving care. Rockville (MD): National Coordinating Council for Medication Error Reporting and Prevention; 2001 Jun 27 [cited 2009 May 5]. p 3. Available from: http://www.premierinc.com/ quality-safety/tools-services/safety/topics/bar_coding/ downloads/ barcoding.pdf

7. Vaccine bar coding initiative in Canada: summary of progress to date. Ottawa (ON): Public Health Agency of Canada; 2007 Jan 5.

8. Pharmaceutical bar coding to improve patient safety: options for technical standards in the Canadian environment. Roundtable discussion paper. Toronto $(\mathrm{ON})$ : Institute for Safe Medication Practices Canada; 2008 Jan [cited 2009 May 4]. Available from: http://www.ismpcanada.org/download/PharmaceuticalBarCodingtoImprovePatientSafetyISMPCanadaJan08.pdf

9. Institute for Safe Medication Practices Canada; Canadian Patient Safety Institute. Pharmaceutical bar coding to improve patient safety: options for technical standards in the Canadian environment. Proceedings of a stakeholder invitational roundtable. Toronto (ON): The Institutes; 2008 Jun [cited 2009 May 4]. Available from: http://www.ismp-canada.org/ download/BarCoding_Roundtable_Proceedings.pdf 
Acknowledgements

ISMP Canada and CPSI gratefully acknowledge the following organizations (listed in alphabetical order) for their generous support of Phases II and III of the Canadian Pharmaceutical Bar Coding Project: Baxter Corporation, Healthcare Insurance Reciprocal of Canada (HIROC), HealthPRO Procurement Services Inc, McKesson Canada, Medbuy Corporation, Pfizer Canada Inc, Pharmaceutical Partners of Canada Inc (PPC), Sandoz Canada Inc, TEVA Novopharm Ltd
Medication incidents (including near misses) can be reported to ISMP Canada in 1 of 2 ways:

- through the secure web portal at http://www.ismp-canada.org/ err_report.htm

- by telephone at 416.733 .3131 or toll-free at 1.866.544.7672 (1.866.54.ISMPC)

\section{CSHP's Online Continuing Education Program}

The Canadian Society of Hospital Pharmacists is pleased to present our third online education course. This session was held during CSHP's 2009 Annual Professional Practice Conference.

\section{Canadian Diabetes Association Clinical Practice Guidelines: From Paper to Patient}

\section{Karen McDermaid, BSc, BSP, ACPR, CDE \\ Regina Qu'Appelle Health Region \\ Moosomin, Saskatchewan}

Accreditation for this course (1 CEU) is available from the Canadian Council on Continuing Education in Pharmacy. To access this free online education session, please visit the CSHP website at: www.cshp.ca/programs/onlineeducation/index e.asp.

Through our online education programs, CSHP continues to deliver innovative educational programs to hospital pharmacists from across Canada. We encourage you to visit us online today!

CSHP... Supporting hospital pharmacists to excel and innovate in collaborative patient care

\section{MERCK FROSST}

The online availability of this course has been made possible through a sponsorship from Merck Frosst. 